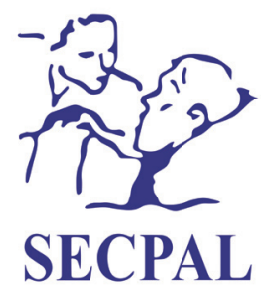

Medicina Paliativa

www.medicinapaliativa.es

IMAGEN DEL MES

\title{
Dermatosis perineal y glútea en un paciente paliativo con rápida respuesta a tratamiento oral
}

\author{
Mercedes Barrio-Gordillo*1 y Olivia López-Barrantes²
}

${ }^{1}$ Hospital Centro de Cuidados, Fundación Vianorte-Laguna, Madrid, España. ${ }^{2}$ Hospital Universitario Infanta Sofía. San Sebastián de los Reyes, Madrid, España

Recibido el 2 de agosto de 2019

Aceptado el 15 de agosto de 2019

Barrio-Gordillo M, López-Barrantes O. Dermatosis perineal y glútea en un paciente paliativo con rápida respuesta a tratamiento oral. Med Paliat. 2019;26(3):257-258.

\section{Descripción del caso}

Mujer de 91 años diagnosticada de carcinoma de rectosigma avanzado. Sin alergias a medicamentos, diabética, hipertensa, con fibrilación auricular, no antiagregada ni anticoagulada por hemorragia digestiva baja y con infecciones urinarias de repetición. Tras empeoramiento e imposibilidad para asumir cuidados en su domicilio, se derivó a una unidad de cuidados paliativos. La paciente, aunque había perdido peso considerablemente en las dos últimas semanas, estaba bien hidratada. Permanecía encamada, estaba orientada y mantenía conversación sencilla. Se objetivó una glositis atrófica y caquexia. De forma llamativa presentaba además una dermatosis hiperémica no exudativa en la región perineal y glútea (Figuras 1 y 2), con bordes netos e irregulares, bilateral de predominio izquierdo. Refería molestias, sin dolor intenso, y no era pruriginosa. No presentaba otras lesiones en su piel.

\section{Resolución del caso}

Se consideró en el diagnóstico micosis, alergia a los pañales o irritación por la incontinencia urinaria. Se le colocó una sonda vesical y trató con antimicóticos tópicos, usándose pañales hipoalergénicos. A pesar de ello, las lesiones no mejoraron nada. Durante dos semanas se aplicaron tratamientos tópicos (pasta lassar, Mephentol ${ }^{\circledR}$, Silvederma ${ }^{\circledR}$, sucralfato), sin obtener ninguna mejoría. Tras ello, se lavó únicamente con agua y jabón y se dejó el pañal abierto para evitar el contacto, manteniendo la sonda vesical. Con estas medidas tampoco se objetivó mejoría.

Se realizó una interconsulta telemática con una dermatóloga, quien determinó como posible causa de la dermatosis una acrodermatitis enteropática. Aconsejó el tratamiento con zinc oral. Se inició tratamiento con una cápsula al día de Zinoxx ${ }^{\circledR}$ (111 mg de zinc gluconato, vit A 0,4 mg, vit E 12 $\mathrm{mg}$, vit B6 0,7 mg). Las Figuras 3 y 4 muestran secuencialmente el resultado a lo largo de 5 días de tratamiento, ya evidenciable tras la segunda dosis.

\section{Discusión/conclusiones}

Los pacientes con enfermedades terminales presentan frecuentes y diversos problemas de la piel debido a sus enfermedades de base y complicaciones de su situación:

\footnotetext{
*Autor para correspondencia:

Mercedes Barrio

Hospital Centro de Cuidados, Fundación Vianorte-Laguna. c/ Concejal Francisco José Jiménez Martín, n. ${ }^{\circ}$ 128, 28047, Madrid, España

Correo electrónico: mbarrio@lagunacuida.org
}

DOI: 10.20986/medpal.2019.1111/2019

1134-248X/ ( 2019 Sociedad Española de Cuidados Paliativos. Publicado por Inspira Network. Todos los derechos reservados. 


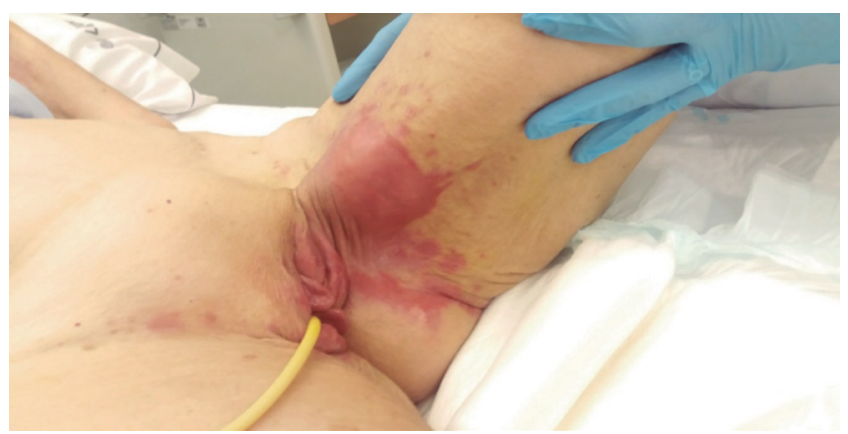

Figura 1.

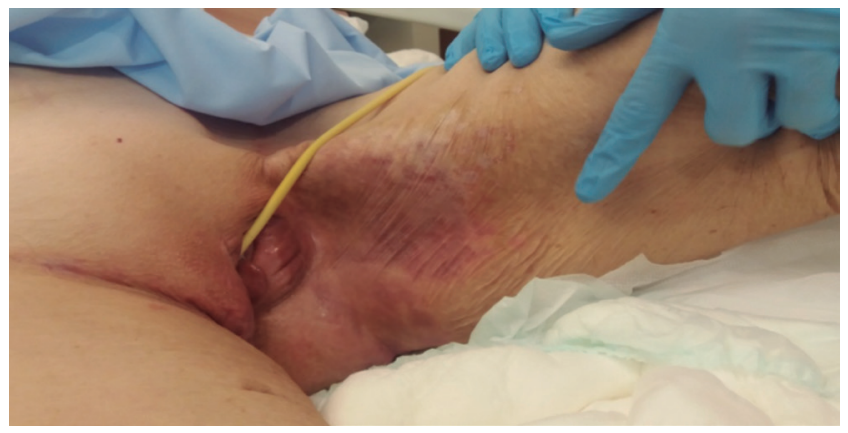

Figura 3.

encamamiento, inmovilidad, malnutrición, incontinencia, etc. Estas lesiones ocasionan importante sufrimiento por el dolor, incomodidad, alteración de la imagen corporal y falta de intimidad. Por lo tanto, su abordaje eficaz por los médicos de cuidados paliativos es prioritario. En algún caso es posible conseguir un tratamiento causal efectivo en el corto periodo de tiempo disponible, como demuestra el paciente descrito.

La acrodermatitis enteropática es una enfermedad rara provocada por déficit de zinc, primaria (enfermedad hereditaria) o secundaria a malnutrición, enfermedades renales, insuficiencia pancreática, etc. ${ }^{1}$. Se caracteriza por lesiones cutáneas con distribución acral y periorificial, alopecia y diarrea ${ }^{2}$. Las alteraciones cutáneas se caracterizan por piel seca, placas eritematosas, costras en región perioral, anogenital, manos y pies. Las lesiones pueden evolucionar a vesículas y erosiones. Las mucosas también se pueden encontrar afectadas, observándose glositis, estomatitis, queilitis angular. Puede progresar con lesiones en rostro y cuero cabelludo y uñas. El diagnóstico es esencialmente clínico, aunque puede estar acompañado de diarrea, alteraciones del estado de ánimo, niveles bajos de zinc y de fosfatasa alcalina (metaloenzima dependiente de zinc) ${ }^{3-6}$.

En el caso de esta paciente, al final de vida, no se determinó zinc en sangre antes de la prueba terapéutica con zinc oral que parece muy probablemente diagnóstica. Los resultados en un corto espacio de tiempo (en 24-48 horas) y el escaso riesgo del zinc oral, avalarían su uso cuando existe sospecha clínica de este cuadro. La dosis de zinc para adul-

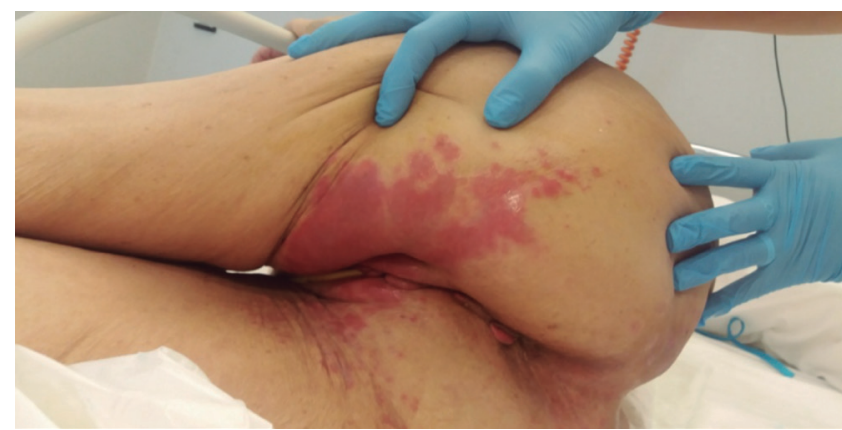

Figura 2.

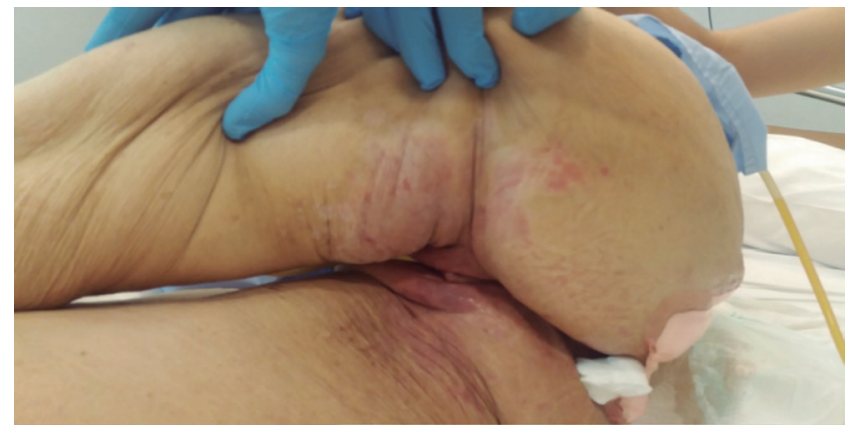

Figura 4.

tos es de 15 a $30 \mathrm{mg}$ al día, en una o dos tomas. La tecnología actual proporciona una gran ayuda en los diagnósticos clínicos dermatológicos. Contar con una adecuada red de comunicación y de consultoría especializada podría mejorar la calidad asistencial de nuestros pacientes.

Nota: se obtuvo el consentimiento verbal para la obtención y uso de las imágenes.

\section{Bibliografía}

1. Maverakis E, Fung MA, Lynch PJ, Draznin M, Michael DJ, Ruben $B$, et al. Acrodermatitis enteropathica and an overview of zinc metabolism. J Am Acad Dermatol. 2007;56:116-24.

2. Bressan Schiavon G, Oliveira de Carvalho V, Parolin L, Taniguchi K, Giraldi S. Acrodermatitis enteropática: descripción de siete casos y revisión de la literatura. Dermatol Pediatr Lat. 2006;4:211-6.

3. Horcajada-Reales C, Barchino-Ortiz L, Conde Montero E, Suárez Fernández R. Acrodermatitis enterophatica in an adult. AFP. 2015;44:299-300.

4. Skrovanek S, DiGuilio K, Baley R, Huntington W, Urbas R, Mayilvaganan $B$, et al. Zinc and gastrointestinal disease. World J Gastrointest Pathophysiol. 2014;5:496-513.

5. Avellaneda C, Cruz CM, Palacio A. Acrodermatitis enteropática, un reto diagnóstico: reporte de caso y revisión de la literatura. Rev Med. 2009;17:150-4.

6. Martínez-Bustamante ME, Peña-Vélez R, Almanza-Miranda E, Aceves-Barriosa CA, Vargas-Pastranad T, Morayta-Ramírez Corona ARR. Acrodermatitis enteropática. Bol Med Hosp Infant Mex. 2017;74:295-300. 